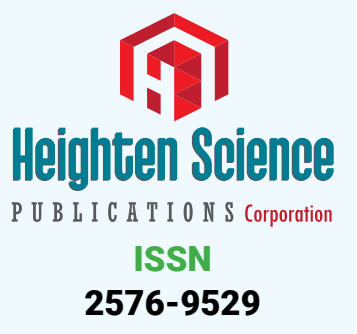

2576-9529

\begin{abstract}
*Address for Correspondence: Shree Patel, Clinical Assistant Professor of Surgery, UIC Department of Surgery, Organ Transplant Clinical Pharmacist, UIC College of Pharmacy, University of Illinois Hospital \& Health Sciences System (UI Health), Chicago, USA, Tel: 312996 1446; Email: spatel64@uic.edu
\end{abstract}

Submitted: 14 August 2018

Approved: 29 August 2018

Published: 30 August 2018

Copyright: @2018 Patel S. et al. This is an open access article distributed under the Creative Commons Attribution License, which permits unrestricted use, distribution, and reproduction in any medium, provided the original work is properly cited. Keywords: Crossmatch; Desensitization; Graft survival; Patient survival

Abbreviations: AMR: Antibody Mediated Rejection; BPACR: Biopsy-Proven Acute Cellular Rejection; BPAMR: Biopsy-Proven Antibody Mediated Rejection; CDCXM: Complement-Dependent Cytotoxicity Crossmatch; XM: Crossmatch; DSADonor-Specific Antibodies; ESRD: End-Stage Renal Disease; eGFR: Estimated Glomerular Filtration Rate; FCXM- Flow Cytometry Crossmatch; HLAHuman Leukocyte Antigens; IVIg: Intravenous Immune Globulin; MCS: Mean Channel Shifts; NXM: Negative Crossmatch; PRA: Panel Reactive Antibody; PP: Plasmapheresis; PXM: Positive

Crossmatch; University of Illinois Hospital \& Health Sciences System (UI Health)
Research Article

\section{Three year outcomes following positive cross match renal transplantation despite failure to convert to Negative Flow Cross Match after Desensitization}

\author{
Shree Patel ${ }^{1 *}$, Jamie Benken², Patricia West Thielke ${ }^{3}$, Sanjeev \\ Akkina ${ }^{4}$, Enrico Benedetti ${ }^{4}$ and James Thielke ${ }^{4}$ \\ ${ }^{1}$ Clinical Assistant Professor of Surgery, UIC Department of Surgery, Organ Transplant Clinical \\ Pharmacist, UIC College of Pharmacy, University of Illinois Hospital \& Health Sciences System (UI \\ Health), Chicago, USA \\ 'Department of Pharmacy, University of Illinois Hospital \& Health Sciences System (UI Health), \\ Chicago, USA \\ ${ }^{3}$ Department of Surgery, University of Illinois Hospital \& Health Sciences System (UI Health), \\ Chicago, USA \\ ${ }^{4}$ Department of Medicine, Nephrology, University of Illinois Hospital \& Health Sciences System (UI \\ Health), Chicago, USA
}

\section{Abstract}

Desensitization allows successful transplantation of patients with a positive crossmatch (PXM) against their live donor. We evaluated outcomes following PXM renal transplant despite failure to convert to negative flow cytometric crossmatch (FCXM) after desensitization. Patients that underwent desensitization before PXM transplant between $1 / 1 / 00$ and $11 / 1 / 11$ were identified for analysis. Patients who received a transplant despite failure to convert to negative FCXM were identified as the not converted group. Patients who converted to negative FCXM after desensitization comprised the converted group control arm. 108 patients were desensitized before PXM transplant, (not converted group $=42$; converted group $=66$ ). Mean eGFR was comparable between groups at all time points, and 3-year eGFR was $57.8 \mathrm{~mL} / \mathrm{min}$ vs. $57.1 \mathrm{~mL} / \mathrm{min}, \mathrm{p}=0.91$. Patients with eGFR $<30 \mathrm{~mL} / \mathrm{min}$ at 3 years did not differ significantly ( $28 \%$ vs. $14 \%, p=0.15)$. Biopsy-proven rejection rates were numerically higher within the not converted group for each type of rejection and time point, but the values did not differ significantly. Opportunistic infections rates were comparable. Patient survival ( $95 \%$ vs. $91 \%$ ) and death-censored allograft survival $(84 \%$ vs. $95 \%, p=0.07)$ were similar between arms at 3 years post-transplant.

\section{Introduction}

Renal transplantation has not only become a widely accepted treatment strategy for patients with end-stage renal disease (ESRD), but also transplantation has shown to be the most advantageous therapy in terms of mortality when compared to dialysis [1]. However, a limited fraction of ESRD patients are transplanted each year, and the discrepancy between donors and recipients is still increasing. Over 84,000 candidates were waiting for a renal transplant at the start of 2011 [2]. However, with approximately 14,000 donors available, less than 16,000 candidates received a living or deceased donor transplant while over 5,000 died awaiting an organ. Taking advantage of the availability of living donors can help reduce this discrepancy, but the situation continues to worsen as the number of sensitized candidates on the waiting list also rises steadily [3].

How to cite this article: Patel S, Benken J, Thielke PW, Akkina S, Benedetti E, et al. Three year outcomes following positive cross match renal transplantation despite failure to convert to Negative Flow Cross Match after Desensitization. J Clini Nephrol. 2018; 2: 029-038. https://doi.org/10.29328/journal.jcn.1001016 
Patients become sensitized via exposure to various human leukocyte antigens (HLA) which can occur following a pregnancy, blood transfusion, or previous transplant [4]. Exposure to these foreign antigens can cause the individual to develop antibodies against these antigens. Antibodies against their specific donor's HLA are termed donorspecific antibodies (DSA). The presence of DSA can lead to a positive crossmatch (PXM). In the past, sensitization has been a contraindication to transplantation because the presence of anti-HLA antibodies puts the recipient at an increased risk for hyperacute rejection, antibody mediated rejection (AMR) and graft loss [5]. Previously sensitized recipients had to wait for a donor to which the XM was negative. As a result, these sensitized individuals experience significantly prolonged wait times versus candidates that are non-sensitized. The median national wait time for a non-sensitized candidate with panel reactive antibody (PRA) of 0 to 9 percent is about 1300 days, while individuals with a PRA between 10 and 79 percent wait a median of approximately 1900 days. Furthermore, this wait time increases to over 3600 days for patients with a PRA of 80 percent or greater [6].

The obstacle of sensitization is slowly being overcome with the introduction of enhanced techniques for the detection and classification of antibodies, kidney paired donation, and desensitization [5]. Desensitization refers to the use of immunomodulators in order to reduce or neutralize the amount of circulating anti-HLA antibodies to levels appropriate for transplant. At the University of Illinois Hospital \& Health Sciences System (UI Health), desensitization protocols consisting of plasmapheresis (PP) and low-dose intravenous immune globulin (IVIg) and have been utilized to successfully transplant patients who have a PXM with their living donor since 2000. Using similar desensitization protocols, a recent study has shown a significant survival benefit with desensitization when compared to waiting for a more compatible organ [7]. However, further advances in desensitization are still needed. The literature to date does not describe how to proceed in the setting of a "borderline" positive flow-cytometry crossmatch (FCXM) after desensitization. Therefore, the purpose of this study is to evaluate outcomes following PXM renal transplantation despite failure to convert to a negative flow cross-match (NXM) after desensitization and to determine what variables correlate with positive or negative outcomes in these patients. The overall goal of the study is to improve the desensitization process at UI Health based on these findings.

\section{Materials and Methods}

\section{Selection and description of participants}

Prior to the commencement of this study, the Institutional Review Board approved this retrospective review as protocol \# 2011-0848. A search of the UI Health transplant records was performed to identify all patients that underwent desensitization prior to a PXM renal transplant between January 2000 and November 2011. Patients with a simultaneous $\mathrm{ABO}$ incompatibility with their donor were not included in the analysis. After desensitization, the patients who failed to convert to NXM by FCXM prior to proceeding to transplant were identified for analysis as the "not converted group". The patients who converted to NXM before proceeding to transplant were identified as the "converted group" and served as the control arm. Demographic data, XM results, and outcome measures such as graft function, patient and graft survival, and episodes of rejection were collected via chart review from December 2011 to December 2014. Episodes of rejection were classified as empiric rejection, biopsy-proven antibody mediated rejection (BPAMR), or biopsy-proven acute cellular rejection (BPACR). Empiric rejection was defined by an unexplained rise in serum creatinine $>25 \%$ (in the absence of calcineurin inhibitor toxicity, dehydration and/or urinary tract complications) that was treated with high-dose pulse steroids, antithymocyte globulin or PP and/or IVIg but never confirmed with renal biopsy. The primary endpoint of this study is mean estimated glomerular filtration rate (eGFR) determined by the Modification of Diet in Renal Disease (MDRD) equation at 1 year. Secondary endpoints included percentage 
of subjects with eGFR $<30 \mathrm{~mL} / \mathrm{min}$, rejection rates, graft and patient survival, and opportunistic infections. These secondary endpoints were assessed at discharge, 3 months, 6 months, 1 year, and 3 years. At UI Health, a positive final B cell FCXM is more commonly accepted for transplantation compared to a positive T cell FCXM. To further investigate the outcomes of this practice, a subgroup analysis of patients with a positive final B cell FCXM was performed.

\section{Crossmatch data}

Both Antihuman globulin (AHG) complement-dependent cytotoxic XM (CDCXM) and flow cytometry XM (FCXM) were performed for each subject, and XM positivity was established if either assay was considered positive. A 256-channel flow cytometer was used to perform FCXM. The flow cytometry XM was considered positive when the mean channel shift (mcs) was greater than 19 channels above the negative control (pooled $\mathrm{AB}+$ normal human serum) for $\mathrm{T}$ cells and greater than 30 channels above the negative control for B cells. The mean channel shift FCXM cut-off values were determined by the histocompatibility laboratory, Gift of Hope Organ \& Tissue Donation Network, Itasca, IL.

\section{Desensitization protocol}

UI Health PXM desensitization protocols have been described in detail previously (8). Each patient received pre-transplant plasmapheresis (PP) every other day for a total of at least 1 to 4 sessions or until the patient converted to a NXM depending on the era in which the patient received the transplant. IVIg was administered after each PP session and dosed at 100-150 mg/kg/dose (based on ideal body weight) depending on the era in which the patient received the transplant. In recent years, the protocol has become more intense with desensitization by extending the number PP sessions and IVIg doses or considering bortezomib in patients who fail to convert to NXM with PP and IVIg alone. Patients were also started on their maintenance immunosuppressants, tacrolimus and mycophenolate, 2 weeks prior to transplant unless impeded by insurance coverage issues. Post-transplant, the protocol dictates that the cycle of PP and IVIg should be continued every other day for a total of at least 5 more PP sessions and 4 additional doses of IVIg.

\section{Induction and maintenance immunosuppression}

UI Health PXM induction and maintenance protocols have been described in detail previously $[8,9]$. All PXM patients received induction with antithymocyte globulin 1.5$2.5 \mathrm{mg} / \mathrm{kg} /$ dose depending on the era in which the patient received the transplant with the first dose being given in the operating room. Subsequent doses are given every other day, on days in which the patient did not receive IVIG, for a total of 5 doses. Maintenance immunosuppression consisted of a combination of tacrolimus and mycophenolate. Methylprednisolone was given $500 \mathrm{mg}$ intraoperatively to all patients. During the first 2 years of the protocol, prednisone was then tapered over a 6 -month period from $1 \mathrm{mg} /$ $\mathrm{kg}$ down to $0.2 \mathrm{mg} / \mathrm{kg}$ daily. Patients were then maintained on $10 \mathrm{mg}$ daily thereafter.

\section{Statistical techniques}

Statistical analysis was performed using SAS software 9.2 (Cary, NC.) Comparisons between groups were done using Chi-square and the Student t-test for categorical and continuous variables, respectively. Analysis of one-way variance was used to examine the association between the predictor variables and kidney function. Logistic regression models were used to examine the effect of the predictor variables on complications including acute rejection. The Cox proportional hazards model was used to examine the relationship between predictor variables on patient and graft survival.

\section{Results \\ Demographics}

A total of 108 PXM patients were transplanted with a desensitization protocol during the study period. Forty-two patients failed to convert to NXM prior to transplant 
comprising the not converted group. Sixty-six patients successfully converted after desensitization comprising the converted group (Figure 1). Figure 1 depicts the disposition of patients including the number of patients available for analysis at each of the time points and the cause for the diminishing patient population as time progressed. Reasons included lost to follow-up, patient death or graft loss. The mean age was similar between groups at about 43 years $(\mathrm{p}=0.71)$ (Table 1$)$. The majority of recipients were female (62\%). The racial distribution of both donors and recipients was also consistent between arms ( $\mathrm{p}=0.7$ ), with the majority of recipients being of African American (45\%) or Hispanic (36\%) descent. This racial distribution is reflective of the patient population at UI Health. The not converted group had a higher number of subjects with a history of previous transplant ( $36 \%$ vs. $15 \%$, $p=0.01$ ) which reflects that these subject were more sensitized and thus more difficult to convert to NXM after desensitization.

\section{Crossmatch data}

Sixty-five percent of patients in the not converted group had positive initial CDC XMs versus $16 \%$ in the converted group ( $\mathrm{p}<0.001$ ). In regards to FCXM, 85\% in the not converted group had positive initial B cell FCXM compared to 53\% in the converted group ( $\mathrm{p}=0.001$ ). Eighty-four percent of subjects had positive initial T cell FCXM in the not converted group versus $97 \%$ within the converted $(p=0.05)$. In both groups, all patients must have converted to negative CDCXM prior to transplantation. Additionally,

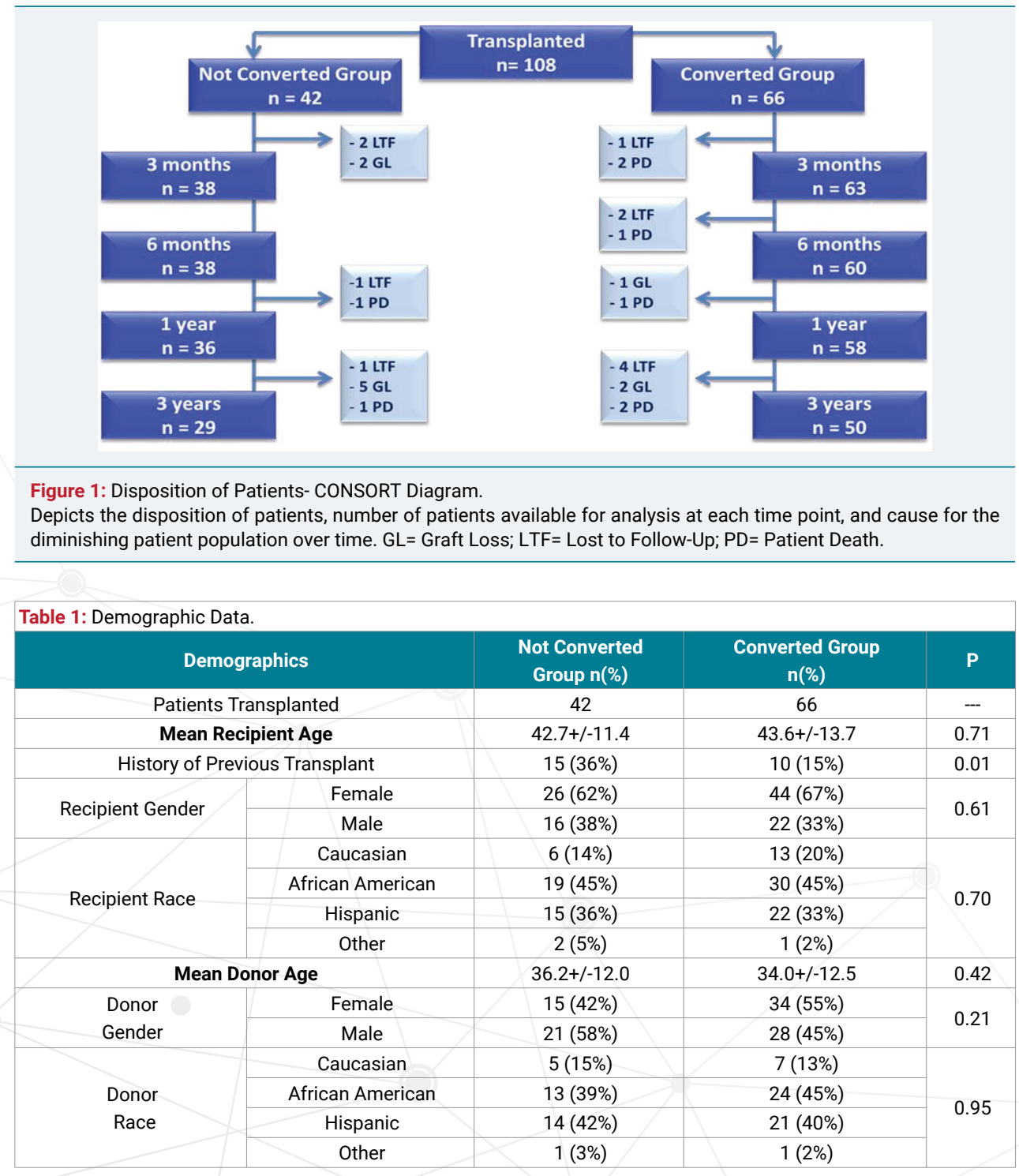


as explained when defining the converted group, no patients had positive final XMs by both CDCXM and FCXM. After desensitization, 55\% and 73\% of patients within the not converted group had positive final B cell and T cell FXCM, respectively $(p<0.01)$. The mean final FCXM values in the not converted group were 8 mean channel shifts above the pre-defined negative control cut-off for both T cells and B cells.

\section{Graft function data}

For the primary outcome measure, mean GFR (mL/min) at 1 year was 51 in the not converted group and 58 within the control group $(\mathrm{p}=0.12)$ (Table 2). This similarity in GFR held true out to 3 years post-transplant ( $58 \mathrm{~mL} / \mathrm{min}$ vs. $57 \mathrm{~mL} / \mathrm{min}, \mathrm{p}=0.91$ ). The secondary outcome of percentage of patients with GFR $<30 \mathrm{~mL} / \mathrm{min}$ was numerically higher in the not converted group, but these values did not differ significantly at all time points. At 3 years, $28 \%$ of patients in the not converted group had a GFR $<30 \mathrm{~mL} /$ min compared to $14 \%$ within the converted group ( $\mathrm{p}=0.15)$.

\section{Rejection data}

Table 3 illustrates the cumulative rejection data for each of the subjects. A single subject could be counted multiple times depending on the type of rejection they experienced. There was significantly more empiric treatment (methylprednisolone 1.5 grams total over 2-3 days) for acute rejection in the not converted group within the first 6 months of transplant ( $41 \%$ vs. $21 \%, p=0.03$ ). Though numerically higher in the not converted group, BPAMR and BPACR rates were not found to be statistically different. At 3 years, $24 \%$ of patients in the not converted group had an episode of BPAMR compared to $18 \%$ within the converted group ( $p=0.48)$. An episode of BPACR was seen in $31 \%$ of patients in the not converted group and $26 \%$ of patients in the converted group at at 3 years $(\mathrm{p}=0.56)$. BPACR was treated with one or more of the following depending on histopathologic grading: methylprednisone 1.5 grams total over 2-3 doses and/or antithymocyte globulin $1.5-2.5 \mathrm{mg} / \mathrm{kg} /$ dose for $4-5$ doses. BPAMR was treated with plasmapheresis every other day for a total of at least 4 sessions. IVIg was administered after each PP session and dosed at 100-150 mg/kg/ dose (based on ideal body weight).

\begin{tabular}{|c|c|c|c|c|}
\hline \multicolumn{2}{|c|}{ Graft Function Data } & Not Converted Group & $\begin{array}{c}\text { Converted } \\
\text { Group }\end{array}$ & $\mathbf{P}$ \\
\hline \multirow{5}{*}{ GFR (mL/min) } & Discharge & $58.8+/-34.6 n=41$ & $71.5+/-31.4 n=65$ & 0.06 \\
\hline & 3 months & $55.0+/-22.3 n=38$ & $57.4+/-19.7 n=63$ & 0.58 \\
\hline & 6 months & $53.2+/-23.6 n=38$ & $59.9+/-19.7 n=60$ & 0.13 \\
\hline & 1 year & $50.7+/-23.7 n=36$ & $58.0+/-20.4 n=58$ & 0.12 \\
\hline & 3 years & $57.8+/-31.4 n=29$ & $57.1+/-24.3 n=50$ & 0.91 \\
\hline \multirow{5}{*}{$\% \mathrm{GFR}<30 \mathrm{~mL} / \mathrm{min}$} & Discharge & $6(15 \%)$ & $4(6 \%)$ & 0.18 \\
\hline & 3 months & $4(11 \%)$ & $4(6 \%)$ & 0.47 \\
\hline & 6 months & $6(16 \%)$ & $2(3 \%)$ & 0.05 \\
\hline & 1 year & $7(19 \%)$ & $4(7 \%)$ & 0.10 \\
\hline & 3 years & $8(28 \%)$ & $7(14 \%)$ & 0.15 \\
\hline
\end{tabular}

Legend: Estimated Glomerular Filtration Rate (eGFR).

Table 3: Cumulative Rejection Data.

\begin{tabular}{|c|c|c|c|c|c|c|}
\hline \multirow{2}{*}{\multicolumn{2}{|c|}{ Rejection Data }} & \multirow{3}{*}{$\begin{array}{c}\text { Not Converted } \\
\text { Group n (\%) } \\
8(19 \%)\end{array}$} & \multirow{3}{*}{$\begin{array}{c}\text { Converted Group } \\
\text { n (\%) } \\
7(11 \%)\end{array}$} & \multirow{3}{*}{$\begin{array}{c}\mathbf{P} \\
0.22\end{array}$} & \multicolumn{2}{|c|}{ Total Rejections } \\
\hline & & & & & \multirow{2}{*}{$\begin{array}{c}\text { Not Converted } \\
9\end{array}$} & \multirow{2}{*}{$\begin{array}{c}\text { Converted } \\
8\end{array}$} \\
\hline & 6 months & & & & & \\
\hline \multirow[t]{2}{*}{ BPACR } & 1 year & $11(26 \%)$ & $10(15 \%)$ & 0.16 & 12 & 11 \\
\hline & 3 years & $13(31 \%)$ & $17(26 \%)$ & 0.56 & 15 & 21 \\
\hline \multirow{3}{*}{ BPAMR } & 6 months & $8(19 \%)$ & $11(16 \%)$ & 0.75 & 8 & 12 \\
\hline & 1 year & $10(24 \%)$ & $11(17 \%)$ & 0.36 & 10 & 12 \\
\hline & 3 years & $10(24 \%)$ & $12(18 \%)$ & 0.48 & 11 & 13 \\
\hline \multirow{3}{*}{ Empiric Rejection } & 6 months & $17(41 \%)$ & $14(21 \%)$ & 0.03 & 18 & 15 \\
\hline & 1 year & $17(41 \%)$ & $20(30 \%)$ & 0.28 & 19 & 22 \\
\hline & 3 years & $20(48 \%)$ & $22(33 \%)$ & 0.14 & 23 & 26 \\
\hline
\end{tabular}

Legend: BPACR- Biopsy-Proven Acute Cellular Rejection; BPAMR- Biopsy-Proven Antibody Mediated Rejection. 


\section{Survival data}

Rates of patient death were comparable between arms for the first 3 years after transplant (Table 4, Figure 2). A total of 2 patient deaths occurred within the not converted group and 6 within the converted group at 3 years. Rates of death-censored graft survival were similar at each time point (Table 4). Figure 3 illustrates rates of death-censored graft survival over time. At 3 years, death-censored graft survival was $84 \%$ in the not converted group and $95 \%$ in the converted group ( $p=0.07$ ). A total of 6 death-censored graft losses occurred within the not converted group and 3 within the converted group at 3 years. Rejection-free survival, including empiric rejection episodes, is depicted in Figure 4 and was higher in the converted group ( $\mathrm{p}=0.01)$.

\section{Opportunistic infection data}

Table 5 illustrates opportunistic infection rates were similar between treatment groups at 3 years follow-up. A total of 15 (36\%) subjects within the not converted group acquired an opportunistic infection compared to 25 (38\%) subjects. Overall incidence of BKV was $14 \%(6 / 42)$ and $26 \%(17 / 66)$ in the not converted and converted group, respectively. Two subjects in the PXM arm and 4 subjects in the converted arm developed BKV nephropathy. In the not converted arm, both cases occurred around 7

\begin{tabular}{|c|c|c|c|}
\hline \multicolumn{2}{|c|}{ Table 4: Survival Data. } & $\begin{array}{c}\text { Not Converted Group } \\
\% \text { (total deaths) }\end{array}$ & $\begin{array}{c}\text { Converted Group } \\
\% \text { (total deaths) }\end{array}$ \\
\hline \multirow{3}{*}{ Patient Survival } & 6 months & $100 \%(0)$ & $95 \%(3)$ \\
\cline { 2 - 4 } & 1 year & $98 \%(1)$ & $94 \%(4)$ \\
\cline { 2 - 4 } & 3 years & $95 \%(2)$ & $91 \%(6)$ \\
\hline \multirow{2}{*}{$\begin{array}{c}\text { Death -Censored } \\
\text { Graft Survival }\end{array}$} & 6 months & $98 \%(2)$ & $100 \%(0)$ \\
\cline { 2 - 4 } & 1 year & $98 \%(2)$ & $98 \%(1)$ \\
\hline
\end{tabular}

Table 5: Opportunistic Infection Data.

\begin{tabular}{|c|c|c|c|}
\hline Opportunistic Infections & $\begin{array}{c}\text { Not Converted Group } \\
\mathbf{n}(\%)\end{array}$ & $\begin{array}{c}\text { Converted Group } \\
\mathbf{n}(\%)\end{array}$ & P \\
\hline Any & $15 / 42(36 \%)$ & $25 / 66(38 \%)$ & 0.82 \\
\hline EBV Viremia & Viral & $0 / 25(0 \%)$ & 0.19 \\
\hline BKV Viremia & $1 / 15(7 \%)$ & $13 / 25(52 \%)$ & 0.12 \\
\hline BKV Nephropathy & $4 / 15(27 \%)$ & $4 / 25(16 \%)$ & 0.82 \\
\hline CMV Viremia & $2 / 15(13 \%)$ & $8 / 25(32 \%)$ & 0.18 \\
\hline CMV Disease & $8 / 15(53 \%)$ & $1 / 25(4 \%)$ & 0.28 \\
\hline PJP & $2 / 15(13 \%)$ & $1 / 25(4 \%)$ & 0.71 \\
\hline Mycobacteria & Bacterial & $1 / 25(4 \%)$ & 0.43 \\
\hline Invasive Aspergillus & $1 / 15(7 \%)$ & & 0.71 \\
\hline
\end{tabular}

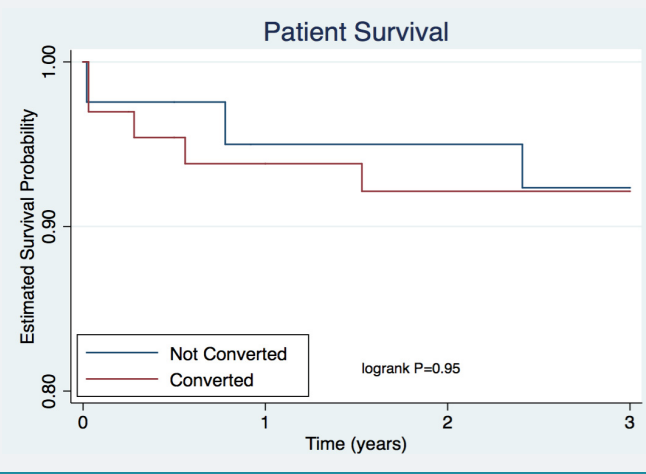

Figure 2: Patient Survival. Depicts estimated probability of patient survival out to three years post-transplant. Cox proportional hazards model was used to examine the relationship between predictor variables on survival. $P=0.95$. 


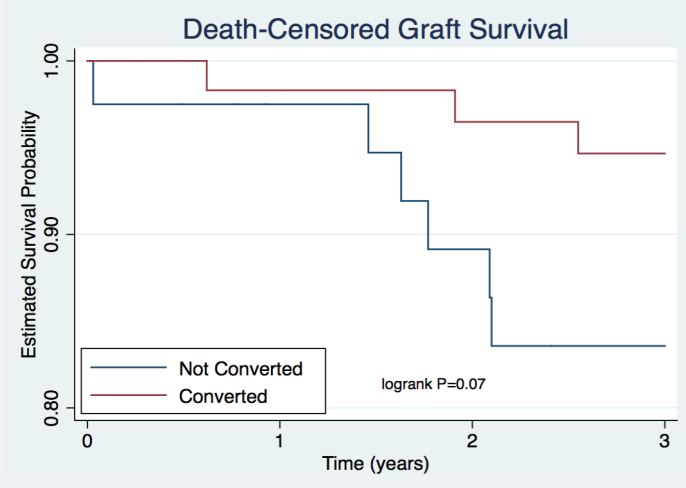

Figure 3: Death Censored Graft Survival. Depicts estimated probability of graft survival out to three years posttransplant. Cox proportional hazards model was used to examine the relationship between predictor variables on survival. $\mathrm{P}=0.07$

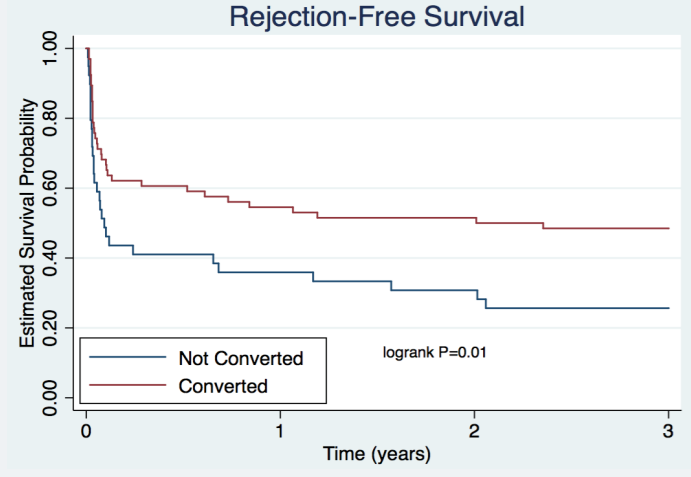

Figure 4: Rejection-Free Survival. Depicts estimated probability of survival without rejection including both empiric and biopsy-proven rejection episodes. Cox proportional hazards model was used to examine the relationship between predictor variables on survival. $\mathrm{P}=0.01$

months after transplant, and both patients continue to have functioning allografts after reduction in immunosuppression. In the converted arm, 2 of the BKV nephropathy cases occurred at approximately 3 months after transplant and 1 case at about 18 months. Allograft function was preserved with the reduction of immunosuppression and/or the addition of leflunomide in all 3 cases. The fourth case occurred at more than 2 years post-transplant. This patient had concomitant ACR requiring treatment with pulse steroids and led to allograft loss. The overall rates of CMV (disease and viremia) were $24 \%(10 / 42)$ and $14 \%(9 / 66)$ in the not converted and converted groups, respectively. Two subjects in the not converted arm developed CMV colitis at approximately 8 months after transplant. Both cases were treated successfully with IV ganciclovir and temporary reduction in immunosuppression. One subject in the converted arm acquired CMV nephropathy at 4 months post-transplant that resolved with IV ganciclovir and temporary reduction in immunosuppression. One patient developed aspergillosis pneumonia in each group.

\section{Bcell FCXM subgroup data}

At each time point, numerically higher incidence of BPACR and BPAMR was seen in the positive final B cell FCXM subgroup versus those who converted to negative B cell FCXM prior to transplant (Table 6). Patient survival and graft survival at 3 years were both $84 \%$ in the positive final B cell FCXM subgroup versus $100 \%$ and $69 \%$, respectively. Additionally, a numerically greater percentage of subjects had GFR < $30 \mathrm{~mL} / \mathrm{min}$ in the final B cell FCXM positive subgroup at 3 years ( $38 \%$ vs. $9 \%, \mathrm{p}=0.18$ ). Nevertheless, all other comparisons were statistically similar within the subgroup analysis including mean GFR, graft survival, and patient survival. 


\begin{tabular}{|c|c|c|c|c|}
\hline \multicolumn{2}{|c|}{ Outcomes } & $\begin{array}{c}\text { B cell Final+ }(n=21) \\
n(\%)\end{array}$ & $\begin{array}{l}\text { B cell Final- }(n=17) \\
n(\%)\end{array}$ & $\mathbf{P}$ \\
\hline \multirow{5}{*}{ GFR } & Discharge & $61.4+/-43.5, n=21$ & $54.1+/-20.4, n=16$ & 0.54 \\
\hline & 3 months & $56.7+/-23.4, n=18$ & $53.8+/-20.9, n=16$ & 0.70 \\
\hline & 6 months & $56.8+/-26.1, n=18$ & $50.7+/-22.0, n=16$ & 0.47 \\
\hline & 1 year & $49.8+/-22.3, n=17$ & $50.7+/-25.1, n=15$ & 0.92 \\
\hline & 3 years & $55.1+/-34.9, \mathrm{n}=16$ & $60.5+/-26.1, n=11$ & 0.66 \\
\hline \multirow{5}{*}{$\%$ GFR<30 } & Discharge & $2(12 \%)$ & $4(19 \%)$ & 0.68 \\
\hline & 3 months & $0(0 \%)$ & $3(18 \%)$ & 0.09 \\
\hline & 6 months & $2(11 \%)$ & $3(18 \%)$ & 0.65 \\
\hline & 1 year & $3(20 \%)$ & $3(18 \%)$ & 1.00 \\
\hline & 3 years & $6(38 \%)$ & $1(9 \%)$ & 0.18 \\
\hline \multirow{3}{*}{ Patient Survival } & 6 months & $95 \%$ & $100 \%$ & \multirow[b]{3}{*}{0.10} \\
\hline & 1 year & $90 \%$ & $100 \%$ & \\
\hline & 3 years & $84 \%$ & $100 \%$ & \\
\hline \multirow{3}{*}{ Graft Survival } & 6 months & $95 \%$ & $94 \%$ & \multirow[b]{3}{*}{0.30} \\
\hline & 1 year & $90 \%$ & $94 \%$ & \\
\hline & 3 years & $84 \%$ & $69 \%$ & \\
\hline \multirow{3}{*}{ BPACR } & 6 months & $6(29 \%)$ & $1(6 \%)$ & 0.10 \\
\hline & 1 year & $8(38 \%)$ & $2(12 \%)$ & 0.14 \\
\hline & 3 years & $8(38 \%)$ & $4(24 \%)$ & 0.49 \\
\hline \multirow{3}{*}{ BPAMR } & 6 months & $5(24 \%)$ & $2(12 \%)$ & 0.43 \\
\hline & 1 year & $6(29 \%)$ & $3(18 \%)$ & 0.48 \\
\hline & 3 years & $7(33 \%)$ & $2(12 \%)$ & 0.15 \\
\hline \multirow{3}{*}{ Empiric Rejection } & 6 months & $8(38 \%)$ & $6(25 \%)$ & 1.00 \\
\hline & 1 year & $8(38 \%)$ & $6(35 \%)$ & 1.00 \\
\hline & 3 years & $9(43 \%)$ & $7(41 \%)$ & 1.00 \\
\hline
\end{tabular}

Legend: eGFR- Estimated Glomerular Filtration Rate; BPACR- Biopsy-Proven Acute Cellular Rejection; BPAMR- BiopsyProven Antibody Mediated Rejection.

\section{Discussion}

The major finding of this retrospective, single-center study is similar mean eGFR in the not converted and converted group at both 1 and 3 years post-transplant. The percentage of patients with eGFR $<30 \mathrm{~mL} / \mathrm{min}$ was numerically higher in the not converted group at 6 months ( $16 \%$ vs. $3 \%, \mathrm{p}=0.05)$. Absolute biopsy-proven rejection rates were also higher within the not converted group for each type of rejection and at each time point. However, these differences were not found to be statistically significant. Patient deaths did not differ significantly between groups. Death-censored graft survival remained comparable, but Figure 3 shows numerically higher rates of death-censored graft survival in the converted group versus the not converted group ( $95 \%$ vs. $84 \%, p=0.07)$. Rejection-free survival was significantly higher in the converted group ( $\mathrm{p}=0.01$ ), but this data may be skewed by the inclusion of empiric rejection rates.

Sensitization, and more specifically a PXM, remains an obstacle to successful renal transplantation. The recent introduction of enhanced techniques for the detection and classification of antibodies, kidney paired donation, and desensitization provide options for circumventing this obstacle [5]. Several transplant centers, including UI Health, have implemented successful desensitization protocols to overcome the barrier of sensitization, utilize more of the living donor population, and prolong survival [3,7,9-11].

The findings presented provoke questions regarding the desensitization protocol at UI Health. Given that the not converted group had clinically inferior outcomes in terms of percentage of patients with eGFR $<30 \mathrm{~mL} / \mathrm{min}$, rejection rates, rejection-free survival and 3-year allograft survival compared to the converted group, should we be stricter in enforcing the conversion to negative FCXM prior to transplantation? The current evidence may not be compelling enough for us to be more conservative by enforcing FCXM cutoffs. Firstly, mean eGFR along with patient survival remained comparable between groups out to 3 years. The patient survival within the not converted group was superior to remaining on hemodialysis. The United States Renal Data System (USRDS) data shows the 3-year survival of an ESRD patient from day one of hemodialysis is 
$50 \%$, and 5-year survival is only $34 \%$ [12]. The 3 -year survival of $95 \%$ seen within our not converted group is a preferred alternative to risking prolonged wait times of 5 to 10 years on the deceased donor list. Secondly, other centers have reported AMR rates between $35.5-39.3 \%$ in desensitized recipients of living donor kidney transplants, and our center has published previous data showing BPAMR rates of $24 \%$ at 1 year after PXM transplantation [9,13-16]. This study found similar BPAMR rates within the not converted group (24\%) and lower rates in the converted group [17-18] at 1 and 3 years. Nevertheless, the rates of longer-term death-censored graft survival and rejection-free survival within the not converted group do further encourage the option of kidney paired donation when feasible.

Additionally, the B cell FCXM subgroup analysis suggests that patients with a greater degree of pre-transplant sensitization represented by a positive final B cell FCXM had similar outcomes to those with a negative B cell FCXM at the time of transplant. A positive final B cell FCXM did correlate with numerically higher rates of BPACR when compared to those who converted to a negative B cell FXCM pre-transplant. Despite these results, mean eGFR at each time point, graft survival, and patient survival were comparable.

This study also confirms previous results from our center which reported similar incidence of opportunistic infections when compared to our patients who do not go through desensitization protocol [9]. In addition, overall rates of both CMV and BKV were similar to those previously reported $[18,19]$. The incidence of progression to BKV nephropathy was also comparable.

Questions that remain unanswered include if there are differences in outcomes in the patients who developed AMR compared to those who did not, and are there differences in rejection rates based on whether the initial standard XM was positive or negative or based on the degree of pre-transplant sensitization.

A significant limitation of this investigation includes a small sample size leading to the possibility for type II error. The power analysis was not performed before analyzing the data. Therefore, we might have been unable to detect significant differences as a result of the small sample size. However, to date, this study has a larger population of PXM data compared to currently available literature. Additionally, the retrospective nature of this study opens up the potential for unrecognized biases or investigator error affecting the outcomes of the two groups. The retrospective design also caused incomplete data collection due to inconsistency in documentation within the electronic medical record. Furthermore, over the time course of the study, DSA were not monitored routinely at UI Health. Therefore, DSA data was unavailable for inclusion in this analysis. Finally, because UI Health protocols did not always dictate protocol biopsies, it is difficult to assess causes of graft dysfunction or failure other than acute rejection such as noncompliance, disease recurrence, calcineurin inhibitor toxicity, infection or transplant glomerulopathy. Additionally, it is difficult to interpret the rejection data due to the high rate of empiric treatment in both arms. Due to these limitations in methodology and statistics, we urge caution when interpreting the findings of our analysis.

\section{Conclusion}

In summary, from the presented results we are able to conclude that mean eGFR was comparable at 6 months, 1 year, and 3 years in the patients that failed to convert to negative FCXM and in those that converted to negative FCXM. Our findings reveal concerning trends in rejection. Numerically higher rates of BPAMR and BPACR were seen within the not converted group. However, BPAMR rates still remained lower than previously reported [9,13-16]. Additionally, the clinically inferior rejection outcomes did not translate into survival, as 1 and 3 year patient survival remained comparable to current trends and was superior to remaining on hemodialysis. This evidence supports the continuation of our practice of proceeding to transplant with borderline positive FCXM after desensitization, as this provides significant survival benefit compared to hemodialysis. 


\section{References}

1. Wolfe RA, Ashby VB, Milford EL, Ojo AO, Ettenger RE, et al. Comparison of mortality in all patients on dialysis, patients on dialysis awaiting a transplant, and recipients of a first cadaveric transplant. $\mathrm{N}$ Engl J Med. 1999; 341: 1725-1730. Ref.: https://tinyurl.com/yadlz3xa

2. Annual Report of the U.S. Organ Procurement and Transplantation Network and the Scientific Registry of Transplant Recipients: Transplant Data 1998-2011. Department of Health and Human Services, Health Resources and Services Administration, Healthcare Systems Bureau, Division of Transplantation, Rockville, MD; United Network for Organ Sharing, Richmond, VA; University Renal Research and Education Association, Ann Arbor, MI. 2011.

3. Gloor J, Stegall MA. Sensitized renal transplant recipients: current protocols and future directions. Nat Rev Neprol. 2010; 6: 297-306. Ref.: https://tinyurl.com/ybwnh996

4. Claas FH, Doxiadis II. Management of the highly sensitized patient. Curr Opin Immunol. 2009; 21 569-572. Ref.: https://tinyurl.com/ya2hk4uo

5. Warren DS, Robert MA. Incompatible kidney transplantation: lessons from a decade of desensitization and paired kidney exchange. Immunol Res. 2010; 47: 257-264. Ref.: https://tinyurl.com/yacwt7f2

6. Organ Procurement and Transplant Network Web Site. 2013.

7. Montgomery RA, Lonze BE, King KE, Edward Kraus S, Lauren Kucirka M, et al. Desensitization in HLA-incompatible kidney recipients and survival. N Engl J Med. 2011; 365: 318-326. Ref.: https://tinyurl.com/y9t75dyb

8. West-Thielke $P$, Herren $H$, Thielke J, Oberholzer J, Sankary H, et al. Results of positive crossmatch transplantation in African American renal transplant recipients. Am J Transplant. 2008; 8: 348-354. Ref.: https://tinyurl.com/ybrpqjal

9. Thielke JJ, West-Thielke PM, Herren HL, Bareato U, Ommert T, et al. Living donor kidney transplantation across positive crossmatch: the University of Illinois at Chicago experience. Transplantation. 2009; 87: 268-273. Ref.: https://tinyurl.com/ybyn9roc

10. Jordan SC, Tyan D, Stablein D, Mclntosh M, Rose S, et al. Evaluation of intravenous immunoglobulin as an agent to lower allosensitization and improve transplantation in highly sensitized adult patients with end-stage renal disease: Report of the NIH IGO2 trial. J Am Soc Nephrol. 2004; 15: 3256-3262. Ref.: https://tinyurl.com/y7ckwke2

11. Jordan SC, Vo A, Bunnapradist S, Toyoda M, Peng A, et al. Intravenous immune globulin treatment inhibits crossmatch positivity and allows for successful transplantation of incompatible organs in living donor and cadaver recipients. Transplantation. 2003; 76: 631-636. Ref.: https://tinyurl.com/y9dukjqm

12. US Renal Data System, USRDS. Annual Data Report: Atlas of Chronic Kidney Disease and End-Stage Renal Disease in the United States, National Institutes of Health, National Institute of Diabetes and Digestive and Kidney Diseases, Bethesda, MD, 2011.

13. Vo AA, Peng A, Toyoda M, Kahwaji J, Cao K, et al. Use of intravenous immune globulin and rituximab for desensitization of highly HLA-sensitized patients awaiting kidney transplantation. Transplantation. 2010; 89: 1095-1102. Ref.: https://tinyurl.com/y72099cc

14. Stegall MD, Gloor J, Winters JL, Moore SB, Degoey S. A comparison of plasmapheresis versus highdose IVIG desensitization in renal allograft recipients with high levels of donor specific alloantibody. Am J Transplant. 2006; 6: 346-351. Ref.: https://tinyurl.com/y8mlat2f

15. Magee CC, Felgueiras J, Tinckam K, Malek S, Mah H, et al. Renal transplantation in patients with positive lymphocytotoxicity crossmatches: one center's experience. Transplantation. 2008; 86: 96103. Ref.: https://tinyurl.com/y6v3wbbd

16. Montgomery RA, Zachary AA. Transplanting patients with a positive donor-specific crossmatch: a single center's perspective. Pediatr Transplant. 2004; 8: 535-542. Ref.: https://tinyurl.com/y7vcnygh

17. Truong LD, Barrios R, Adrogue HE, Gaber LW. Acute antibody-mediated rejection of renal transplant: pathogenetic and diagnostic considerations. Arch Pathol Lab Med. 2007; 131:1200-1208. Ref.: https://tinyurl.com/y7jv4vsj

18. Hirsch HH, Randhawa P. AST Infectious Diseases Community of Practice. BK virus in solid organ transplantation. Am J Transplant. 2009; 9: 136-146. Ref.: https://tinyurl.com/yag92tsd

19. Humar A, Snydman D. AST Infectious Diseases Community of Practice. Cytomegalovirus in solid organ transplant recipients. Am J Transplant. 2009; 9: 78-86. Ref.: https://tinyurl.com/y9g5adqs 